\title{
La responsabilidad educativa de la televisión desde la perspectiva de género en la Península Ibérica.
}

\section{The educational responsibility of television from a gender perspective in the Iberian Peninsula.}

\section{A responsabilidade educativa da televisão desde a prespetiva de genero, na Peninsula Ibérica.}

\author{
Vera Cristina Vieira Ribeiro ${ }^{1}$ \\ Universidad de Valladolid (España) \\ cristina.veraribeiro@gmail.com
}

Fecha de recepción: 25 de agosto de 2020

Fecha de recepción evaluador: 27 de agosto de 2020

Fecha de recepción corrección: 29 de agosto de 2020

\begin{abstract}
Resumen
En este estudio se base en el concepto de género, es una perspectiva de la representación de la mujer en los medios de comunicación. Se profundizará, en la imagen objetiva y subjetiva que representa la identidad del femenino, de las mujeres, la forma de cómo se presenta la mujer, en qué contexto y significado. Esas instrucciones nos dan la representación social presente en el inconsciente colectivo sobre las mujeres y, sobre todo, cual el significado que se da al papel de la mujer en la sociedad.
\end{abstract}

Palabras clave: género, servicio público, igualdad, televisión, mujer

\footnotetext{
${ }^{1}$ Vera Cristina Vieira Ribeiro ha trabajado como Productora en Radio Televisión Castilla y León. Es Profesora por el Ministerio Público Portugués y actualmente se desempeña como Directora; Productora y Periodista en Mindalia.com. ORCID: https://orcid.org/0000-0001-5574-1699
} 


\begin{abstract}
In this study, it is based on the concept of gender, it is a perspective of the representation of women in the media. The objective and subjective image that represents the identity of the feminine, of, woman, the way in which women present themselves, in what context and meaning, will be deepened. These instructions give us the social representation present in the collective unconscious about women and, above all what the meaning is given to the role of women in society.
\end{abstract}

Keywords: gender, public service, equality, television, women

\title{
Resumo
}

Este estudo baseia-se no conceito de género, é uma prespectiva da representação da mulher nos meios de comunicação. Irá-se aprofundar na imagem objetiva y subjetiva que representa a identidade do femenino, las mulheres, en que context e que significado. Estas indicações dão a representação social presente no inconsciente colectivo sobre as mulheres e sobretudo, de qual o significado que se dá ao papel da mulher na sociedade.

Palavras-chave: genero, serviço público, igualdade, televisão, mulher.

\section{Introducción}

En el panorama televisivo los datos indican que las mujeres son más consumidoras de la televisión que los hombres, por eso en este estudio que ha querido comprender el impacto que puede tener el tipo de contenidos que emiten. Además, vamos a instigar la importancia del contenido que se emite tiene en las sociedades y que representación da de la mujer. Intentando señalar si la imagen de la mujer es constructiva, educativa o más bien nos demuestra un papel superficial del femenino.

El contexto televisivo tiene un carácter cada vez con más importancia en las rutinas diarias de los individuos, bien sea como forma de información o de entretenimiento. Las sociedades modernas están sumerjas de información que llega cada vez de forma más rápida y a través de medios y redes. Por eso, cada es muy importante el papel y responsabilidad reguladora de las empresas de comunicación. Vemos por el mundo movimientos importante para fortalecer el tema de igual de género, es cada vez más fuerte esta tendencia. Pero que la cuestión, que están haciendo los medios de comunicación, alimentando la igualdad o desigualdad. Qué imagen se está transmitiendo de la mujer, que papel, que rol, es lo que este estudio quiere reflexionar.

\section{Metodología}

La discusión de la perspectiva de género en la televisión que esta publicación basó su evidencia se ha hecho desde una visión de revisión bibliográfica. Se ha analizado y señalado varios artículos y publicación de varios autores de diferentes países con el principal enfoque de encontrar una fuerte tendencia en los medios de la imagen de la 
mujer. Reflexionar sobre las tendencias de las imagines y posiciones adoptadas, en los medios, que nos llevan a profundizar sobre el papel social de las mujeres y de qué manera se cumple la tendencia igualitaria que se presenta en las sociedades actuales.

\section{Discusión}

En general, en el panorama televisivo, las mujeres consumen más televisión que los hombres: media hora más al día, lo que explica el carácter "femenino" de la televisión. (Torres, 2011, p. 74) Son ellas que dedican más de su tiempo delante de la televisión, principalmente en los horarios de los programas que se analizaran en esta investigación. Por eso es importante analizar cómo se representa este segmento de la población, qué tipo de contenidos se dedican a ellas y si ofrecen una visión plural o estereotipada de las mujeres.

La evolución de la imagen y del papel de la mujer ha sido consolidada y favorecida hasta cierto punto, por un sistema económico que logró aprovechar sus periodos de expansión. Haciendo suyas las características del nuevo modelo de mercado, las revistas, y los programas especialmente dedicados a la mujer llegaron a admitir como eje de la organización de los temas, los interrogantes y los conflictos ligados a ese nuevo perfil femenino. (Mattelart, 1976, p. 9)

Sabemos del poder que los medios de comunicación tienen, siendo una gran influencia social, además de que son a la vez, el reflejo de esa misma sociedad bien sea de forma individual y o colectiva. El medio que se afirma por encima de todos los medios es la televisión que entra en lo más íntimo, el hogar y con el desarrollo tecnológico, ahora está siempre presente. Su importancia determina dos tendencias que aparentemente parezcan opuestas desvelan como vive actualmente el sistema audiovisual.

Así, por una parte, la televisión sigue la tendencia que el telespectador quiere ver, ya que vive de las audiencias, es por eso se ve manifestado el comportamiento de la sociedad. Se ven los valores de determinan esa sociedad, se ve lo real. No es casualidad que el servicio público no esté valorado socialmente, eso es el reflejo de la sociedad consumista en la cual vivimos, en que los individuos viven obsesionados por realizar sus deseos materiales.

Sin embargo, también hay un gran esfuerzo en modelar a la audiencia a imagen de las líneas editoriales. A los medios no les es conveniente crear una audiencia crítica, porque si suelen estar bajo los intereses de las clases dominantes, no les interesa que la gente piense, sino que consuma y no clame. En esta dualidad entra la ética y la responsabilidad que el Estado entrega a los medios, en este caso, cadenas generalistas, que debería ser la prioridad y si no lo es las organizaciones reguladoras tendrían la obligación de actuar.

En este contexto, la mujer es representada en los medios de comunicación, especialmente en ciertos programas, como amas de casa o seductoras, pero las mujeres también son profesoras, médicas, arquitectas, científicas, etcétera. Y eso apenas sale en los medios y pareciera que apenas les interesa hablar de los logros de las mujeres, ya que las siguen representando y tratando como incultas, víctimas, objetos del deseo. 
Una atenta mirada a los datos desvela que las mujeres siguen siendo representadas (en la mayoría de los casos) como amas de casa, como objeto del placer masculino, como seres pasivos cuyo valor se mide por el aspecto físico. También los hombres, en general, son representados siguiendo estereotipos como la fuerza, la dominación, la acción y la incapacidad de ocuparse del cuidado familiar (Alexanian, 2009, p. 1).

La investigadora Gena Corea, (citada por Gonzalo Abril, en su libro Teoría general de la información) expuso lo que para ella son las situaciones más comunes en que aparecen representadas las mujeres en los medios de comunicación: por su belleza, por ser la esposa de alguien importante, por ser actriz o cantante, o por tener un papel de víctima. A partir de aquí, la autora estableció tres tipos básicos de representaciones de las mujeres en los medios:

- Las mujeres neutrales: se incluyen las que son personalidades públicas. Responsabilidad pública significativamente menor que la de los hombres.

- Las mujeres estereotipadas: aquellas que tienen una pareja el cual es un personaje público y gracias a él. También son destacadas por su belleza.

- Las mujeres que aparecen como víctimas: aquellas que aparecen en noticias sensacionalistas o espacios dedicados a temas femeninos. En este grupo las mujeres son representadas normalmente en la vida privada, es decir, como amas de casa. Mientras que el hombre aparece como protagonista de la esfera pública hablando de negocios, política, entre otros.

Otra aportación importante sobre la visión de género es la de Gaye Tuchman y su concepto de "aniquilación simbólica de la mujer" en los medios de comunicación. Según el cual esta representación está sujeta a los papeles fundamentales: seductora u objeto del deseo masculino o "ángel del hogar". Según la autora esta perspectiva "pone en peligro el desarrollo social, al no mostrar las imágenes positivas del conjunto de la sociedad que permitan representaciones adecuadas del colectivo femenino en las actuales sociedades democráticas" (Rovetto, 2010, p. 45).

Varios autores, investigadores del tema de género, como son ejemplo: Eva Navarro Martínez (2011), Aquilina Fueyo Gutiérrez (2011), Antonia Ramírez García(2012), Paula Renis Arellano (2012), Josefina Santibáñez Vilella (2012), Florencia Rovetto (2010), Joaquina Martínez Almeria (1997), María José de los Ríos (1997), Amanda Alexanian (2009), Michèle Mattelart o Felisbela Lopes (2007/2011), defienden que aparte de reproducir los modelos femenino o masculino, la televisión crea modelos, quiere decir que el medio influencia o alimenta las tendencias y comportamiento socialmente establecido en la pantalla. Es en este encuadramiento que surge la responsabilidad que los medios de comunicación tienen en lo que se refiere a la formación de la sociedad. Pero, en caso particular de las cadenas públicas o privadas, no tienen gran 
interés en cambiar su política comercial, en favor de una preocupación con las minorías o estereotipos.

Las televisiones públicas, así como las privadas, responden a las leyes del mercado en la búsqueda de audiencia y ganancia económica. Y las grandes industrias mediáticas, que tienen cada vez más monopolizado el mercado audiovisual, no están dispuestas a ceder parte de su autonomía comprometiéndose hacia una comunicación con perspectiva de género (Alexanian, 2009, p. 2).

Algo se ha hecho internacionalmente en este sentido, se aprobó en la Cuarta Conferencia Mundial sobre la Mujer celebrada en Beijing en 1995, la creación de la Plataforma de Acción. La necesidad surge porque "189 Estados miembros de la ONU reconocieron el papel importante que juegan los medios de comunicación en la representación de las mujeres" (Alexanian, 2009, p. 2).

Entre las doce áreas de preocupación que la Plataforma identifica como centrales para el adelanto de las mujeres, encontramos el punto $\mathrm{J}$ titulado "La mujer y los medios de comunicación". A partir de este fundamental documento internacional, el ámbito de la comunicación adquiere estratégicamente el mismo nivel de importancia otorgado a la economía, la participación política, la violencia o la salud de las mujeres (Alexanian, 2009 , p. 3)

Este documento ha señalado que en los medios la imagen que aparece de las mujeres no favorece desarrollo social de esa imagen, eso se debe también a que existen pocas mujeres trabajando en los medios, principalmente en cargos directivos. Así que esa es una de las causas para que se siga viendo "una imagen muy degradante de las mujeres. De hecho, en Beijing se dejó claro que las mujeres no son ni protagonistas ni sujetos de los medios y, cuando se les representa, se hace con una mirada profundamente sexista" (Alexanian, 2009, p. 3).

Los diferentes Estados miembros poco han hecho en sus países para seguir las orientaciones de la Plataforma, pero a nivel internacional la sociedad civil ha creado iniciativas para continuar profundizando en el tema. Varios estudios se han realizado a nivel académico, dos estudios se han realizado en Portugal y España que es interesante subrayar por su similitud. A lo largo de casi un año, entre septiembre de 2010 y junio de 2011, han sido estudiados los perfiles de los invitados en los telediarios de las tres cadenas generalistas (RTP1, SIC e TVI) y tres temáticos (de información) que pertenecen a las tres cadenas generalistas SICN, RTPN e TVI 24). El análisis señaló que de "1673 programas, en que han participado, 2158 invitados, 1812 son hombres y 346 son mujeres" (Lopes, 2011). Curiosamente, la cadena pública portuguesa ha sido la que más invitadas mujeres ha tenido.

En España, el análisis publicado por el Consell de l'Audiovisual de Catalunya, analiza los telediarios de seis televisiones durante un periodo de tres meses. La presencia de las mujeres resulta ser de un $27,5 \%$ contra un $72,5 \%$ de presencia masculina. Incluso, resulta que más de la mitad de la unidad informativa se refiere exclusivamente a los hombres, el 39,5\% hace referencia a mujeres y hombres indistintamente y un 8,7\% sólo menciona a las mujeres. Así que, se podría concluir que los dos países están con la misma 
realidad en lo que se refiere a la presencia de las mujeres en estudio, en este caso, de los informativos, que seguramente también ocurrirá en los demás formatos.

Profundizando un poco más sobre el tema de la responsabilidad que tienen los medios, o en este caso en específico, la televisión a la hora de elegir bien sean los profesionales, invitados, directivos o contenidos, no están libres de que el hombre y la mujer son seres diferentes. La naturaleza ha dado al hombre y a la mujer, físicamente características diferentes, intereses distintos, formas y necesidades opuestas, pero lo que importa discutir es que, aunque existan diferencias la igualdad de oportunidades debería ser un hecho.

Las mujeres y los hombres hemos ido adquiriendo unas formas de pensar, de relacionarnos, de hacer, de divertirnos, de trabajar...; es decir, unas formas generales de estar en el mundo, de vivir, que, por diversos factores de este proceso, han colaborado a que hoy, el colectivo de las mujeres y el de los hombres tengamos una experiencia histórica muy distinta. (Ríos \& Martínez, 1997, p. 97)

En general, los medios de comunicación se quitan de la responsabilidad de educar o formar la sociedad, pero varios autores defienden que la obligación legal o moral debería existir y permitir una sociedad más equilibrada en valores o derechos. Incluso, como señala Gutiérrez y Navarro (2011) es urgente que los profesionales tengan formación en la perspectiva de género, de forma que propongan y traten contenidos que traten y representen a hombres y mujeres de forma igualitaria y equilibrada.

Es, por tanto, fundamental que este periodismo evite un sesgo sexista (desde los propios contenidos que se elijan como noticiosos hasta el modo de representar a sus protagonistas a través del lenguaje audiovisual o verbal), que pueda fomentar estereotipos sobre los hombres y las mujeres en el ámbito de la educación. Por tanto, no habrá información eficaz si ésta no tiene en cuenta a los diferentes actores que intervienen en ella, así como a los múltiples receptores de la misma (mujeres y hombres). (Fueyo \& Navarro, 2011, p. 263)

En la pantalla se sigue viendo las mujeres en las noticias como víctimas de agresión, bien sea física, sexual, psicológica, o política, representa en la mayoría de los casos un sujeto negativo. Además, la publicidad es un vehículo que enseña fuertemente el modelo estereotipado de la mujer, una visión sexista de la mujer, una «figuras para agradar».

Así, frecuentemente prevalece la consideración de la mujer como objeto sobre la persona, utilizando su cuerpo como reclamo publicitario: la imagen de la mujer sigue siendo utilizada para vender más y mejor cualquier producto. Se la sigue presentando como «reina de la casa» (aunque tímidamente comienzan a aparecer hombres realizando tareas domésticas); sus problemas, los domésticos y su recompensa, tener un hogar resplandeciente y ordenado; pero, sobre todo, debe ser bella, delgada, elegante... condiciones ineludibles para triunfar en cualquier campo y para ello se le presentan infinidad de productos como cremas milagrosas, adelgazantes, perfumes, pantys, etc. (Ríos \& Martínez, 1997, p. 98) 
Teniendo en cuenta, la realidad portuguesa, como ejemplo, la igualdad entre mujeres y hombres es un principio de la Constitución portuguesa, reiterada por varios compromisos adoptados en numerosos foros internacionales, entre los que se encuentran: la Carta de las Naciones Unidas, la Declaración Universal de los Derechos Humanos, la Convención sobre la Eliminación de todas las Formas las Formas de Discriminación contra la Mujer; el Convenio Europeo de Derechos Humanos; la Carta Social Europea y la Declaración de Acción de la Plataforma de Acción de Beijing. Estos documentos, y otros, como la Estrategia de Lisboa (2000), el Plan de Trabajo para la Igualdad entre Mujeres y Hombres (2006-2010) y el Pacto Europeo por la Igualdad de Género (2006), defienden la centralidad y la política de incorporación por la igualdad de género en la estructura de gobierno.

Dicho lo anterior, sería de esperar que algo que está tan legislado en tantas instancias nacionales e internacionales fuese algo profundamente enraizado en la sociedad civil. Sin embargo, esto no es lo que ocurre, en Portugal un país que sigue todavía profundamente machista y en muchos casos, es la mujer que defiende a su agresor.

La encuesta nacional sobre la violencia de género, que se celebró en Portugal, en todos los distritos del continente, en 2007, cuyos participantes eran mujeres mil y mil hombres de 18 o más años de edad, se identificó que una de cada tres portuguesas es víctima de la violencia, que se produce en el ámbito privado, y los autores del crimen son parejas o antiguas parejas, (Lisboa, 2008)..., muestran que el $21 \%$ de las mujeres encuestadas, 18 o más años que fueron víctimas de la violencia, buscó tratamiento en el hospital como consecuencia de la agresión (Carmo, 2006). (Leal, Lopes \& Gaspar, 2011, p. 2) (Traducción propia)

Los programas magazine en la televisión generalista reflejan esta realidad de varias formas, casi a diario en la sección crónica criminal hay un caso de violencia de género, en que un comentador habla y explora el tema dando su opinión de los hechos. Por otra parte, los contenidos de testimonios de mujeres a menudo están hechos por las propias víctimas porque han sido abandonadas o traicionadas o incluso violentadas. También se verifica en los programas una fuerte tendencia de los presentadores en estereotipar y pasar la imagen de la mujer como la que está en casa, se dedica a los hijos y no tiene gran interés por crecer intelectualmente.

En Portugal, según un estudio realizado por Felisbela Lopes, entre 1993 y 2005, los principales invitados de los programas de información eran hombres que tenían puestos profesionales con estatuto elevado. En particular, se trata de políticos que se destacaron en diferentes órganos de poder, con importantes cargos públicos, con los dirigentes de las estructuras sindicales más representativas e interlocutores que tenían profesiones como académicos, médicos, economistas, militares, etcétera (Lopes, 2007, p. 2).

En los programas talk show, las mujeres han sido invitadas sobre la base de la "historia" que tenían que contar. No había interés en su profesión o su estatus sociocultural, porque lo que si hay una cierta experiencia valorada que reportó un registro casi siempre emocional (Lopes, 2007, p. 3) (Traducción propia). 
Por su parte, los programas talk show, es decir, las emisiones con un fuerte componente de entretenimiento y enfoque temático en el ámbito privado, la predominancia es que se invitan las mujeres. Este lugar privilegiado en estos programas se justifica por sus interesantes historias de vida y por la emoción que ellas provocan. Poco se dice de su identidad profesional o importancia, únicamente se señala y enfatiza su experiencia en cuanto ser sensible y se relata casi siempre en un registro emocional.

Se puede decir, que al menos desde el punto de vista de cómo se refleja la sociedad portuguesa (el punto de pluralidad social) estos programas no fomentan el pensamiento crítico, no reflejan la pluralidad social, no reflejan la realidad. Los logros de mujeres y minorías siguen invisibles y se siguen perpetuando los roles tradicionales, que no se corresponden del todo con la realidad social de nuestra época.

En el aspecto de la violencia de género, esto se nota de una forma bastante evidente, además, es un asunto muy grave en Portugal, ya que el carácter machista de la sociedad lo acentúa, pues hay muchos casos de mujeres maltratadas. La importancia de los análisis de género reside en que muestran si en los debates televisivos sobre estos temas realmente profundizan en las causas y los consideran un problema de una sociedad androcéntrica y patriarcal, o lo consideran como problemas aislados, de "algunas mujeres", sin educación y con pocos recursos económicos, o con algún problema social.

Lo que crea algunas reservas es el hombre público en oposición a la mujer privada que vino a engrosar la información semanal de los programas de los canales generalistas. Este binomio señala una división arcaica del desarrollo social, que permanece arraigado en la era posmoderna, donde el desempeño profesional, el poder y el éxito son rasgos intrínsecos a la masculinidad, mientras que la vida familiar, la íntima y relacional son elementos estructurales de la femineidad. (Lopes, 2007, p. 8) (Traducción propia)

Algunos autores se arriesgan a crear alternativas para una educación no sexista, porque, aunque existan inúmeras leyes sobre el tema, se ha comprobado a lo largo del tiempo que eso no es suficiente. Es indispensable que exista un cambio social y de mentalidad, principalmente, en el núcleo famular, en que se ofrece a los más jóvenes la consciencia de igualdad de los géneros "no tendría lógica criticar actitudes sexistas en los medios de comunicación si en casa se trata de forma diferente a la niña o al niño por el hecho de serlo" (Ríos \& Martínez, 1997, p. 99).

Este cambio tardará en suceder el mismo tiempo que la valoración del concepto de servicio público y su valoración por parte de los ciudadanos. Mientras no se produzca este cambio, continuaran las reflexiones sobre la influencia que los medios y la publicidad ejercen sobre la sociedad.

Sería aconsejable que estuviéramos presentes en algunos ratos en que acostumbran a ver la televisión y en ellos:

- Acostumbrar a nuestras hijas e hijos a ver la televisión en postura activa, de forma que su sentido crítico les ayude a discernir lo que es interesante o positivo de lo que no lo es. 
- Cuestionar las imágenes de los anuncios: ante juegos y juguetes que representen imágenes estereotipadas de niñas jugando a casitas, a cuidar bebés, con tocadores para estar bellas, o niños siempre con determinados juguetes, construcciones, etc.

- Hacer ejercicio de invertir los papeles a quienes protagonizan una historia para averiguar si hay un tratamiento discriminatorio.

- Enseñarles a desconfiar de los mensajes publicitarios, a «ver» la publicidad de televisión y criticar sus imágenes: ¿qué pretenden vender en un anuncio determinado?, ¿a quién se dirige?, ¿qué imágenes y recursos utilizan?, así como si estamos de acuerdo con ellas. Si creemos de verdad que mujeres y hombres tienen iguales derechos, debemos fomentar, a todos los niveles, que se les reconozca un mismo papel social: igualdad en responsabilidad e inteligencia, igualdad en aspiraciones y deseos, igualdad en la confianza que deben de tener en sí mismos/as. (Ríos \& Martínez ,1997, p. 100)

Después del desarrollo de las ideas anteriores, es importante subrayar la importancia de formar también a los profesionales de la comunicación y sobre todo que a la hora de escribir las noticias tengan en cuenta las peculiaridades y el enfoque de igualdad. Esta será una de las formas de contribuir para que los contenidos sean emitidos con los mismos valores morales y de igualdad, bien sean hechas por hombres o por mujeres.

Puesto que el sexismo puede ser generado tanto por hombres como por mujeres, contribuir a la igualdad de género y reflexionar sobre el proceso de construcción de noticias y sus impactos en la equidad, debiera ser un desafío para toda la comunidad periodística. (Fueyo \& Navarro, 2011, p. 261)

Por otra parte, es conveniente señalar que el tema de la igualdad a la hora de enfocar los contenidos no es solo tarea de los profesionales de los medios, sino también de las entidades educacionales y legisladoras de los medios. Una vez más la formación es la clave para solucionar el desequilibrio que todavía se verifica en los contenidos.

Hay graves carencias respecto al grado de competencia en comunicación audiovisual, entendida como la capacidad para interpretar mensajes audiovisuales de manera reflexiva y crítica y para expresarse a través del lenguaje audiovisual con unos mínimos de corrección y creatividad. Las necesidades de formación afectan a las seis dimensiones que componen dicha competencia: estética, lenguajes, ideología y valores, recepción y audiencia, producción y programación y tecnología (Santibáñez, Arellano \& García, 2012, pp. 50-51).

La Educomunicación y la Alfabetización Mediática con perspectiva de género, o más bien, que lleva esta perspectiva incluida se revela como una herramienta fundamental para detectar si las representaciones de los diversos actores sociales son justas, adecuadas a la realidad, plurales e imparciales, y por tanto si los medios respetan los valores de servicio público que se suponen en la base de estos medios.

Ello exige una significativa transformación del planteamiento de los currículos educativos, en cualquier nivel y muy especialmente en Primaria y Secundaria, en consonancia con el desarrollo de la alfabetización mediática que se entiende como la capacidad de comprender y valorar críticamente los diversos aspectos de los diferentes medios de comunicación, consiguiendo filtrar adecuadamente la información recibida a través del torrente de datos y de imágenes (Santibáñez, Arellano \& García, 2012, p. 52). 


\section{CONCLUSIONES}

Las principales conclusiones de este estudio indican que, en el panorama televisivo, las mujeres consumen más televisión que los hombres: media hora más al día, y eso de cierta forma explica el carácter "femenino" de la televisión y sobre todo de algunos programas. Sabiendo de la influencia social que tienen los medios de comunicación, y sobre todo la televisión, ya que, es el medio que se afirma por encima de todos los medios porque entra en lo más íntimo, el hogar. Por eso, su responsabilidad de fomentar valores de igualdad de oportunidades y reconocimiento está en evidencia.

Sin embargo, algo que también se concluye en este estudio, es que la televisión y los medios en general, siguen la tendencia de dar al público aquello que él quiere ver, escuchar o leer, dejando defraudada su función educativa. De esta manera, los medios de comunicación terminan siendo el reflejo de la sociedad, sea de forma individual y o colectiva. Dando fuertes indicadores, del nivel, cultural, económico, social, político, etcétera.

Es evidente que esta tendencia ocurre porque a los medios no les es conveniente crear una audiencia crítica, porque suelen estar bajo los intereses de las clases dominantes, y lo que interesa a las clases dominantes, es que los individuos no piensen, sino que consuman y no clamen. Aquí debería intervenir el Estado con sus organizaciones y sistemas reguladores, para exigir el cumplimiento de las funciones educativas e informativas. Sin embargo, eso no ocurre las diferentes instituciones no actúan porque las clases dominantes están en el sistema político, incluso en las entidades regularas de los medios, por ello no actúan cuando su función es exigir el cumplimiento de los intereses educacionales, culturales y evolutivos del ser humano.

La forma como se representa la mujer en los medios de comunicación, especialmente en ciertos programas, sobre todo, como amas de casa o seductoras, pero las mujeres también son profesoras, médicas, arquitectas, científicas, etcétera. Y eso apenas sale en los medios y pareciera que apenas les interesa hablar de los logros de las mujeres, ya que las siguen representando y tratando como incultas, víctimas, u objetos del deseo. Por eso, autores y autores como Gaye Tuchman, reflexionan sobre el concepto de "aniquilación simbólica de la mujer" en los medios de comunicación. Según el cual esta representación está sujeta a los papeles fundamentales: seductora u objeto del deseo masculino o "ángel del hogar". Esta perspectiva "pone en peligro el desarrollo social, al no mostrar las imágenes positivas del conjunto de la sociedad que permitan representaciones adecuadas del colectivo femenino en las actuales sociedades democráticas."

En varias organizaciones, instituciones se habla de papel o rol de la mujer, incluso se aprobó en la Cuarta Conferencia Mundial sobre la Mujer celebrada en Beijing en 1995, la creación de la Plataforma de Acción. La necesidad surge porque "189 Estados miembros de la ONU reconocieron el papel importante que juegan los medios de comunicación en la representación de las mujeres" Pero los diferentes Estados miembros 
poco han hecho en sus países para seguir las orientaciones de la Plataforma, aunque a nivel internacional la sociedad civil ha creado iniciativas para continuar profundizando en el tema. Varios estudios se han realizado a nivel académico, dos estudios se han realizado en Portugal y España que es interesante subrayar por su similitud.

Esos estudios confirman que los principales invitados de los programas de información son hombres que tienen puestos profesionales con estatuto elevado. En particular, se trata de políticos que se destacaron en diferentes órganos de poder, con importantes cargos públicos, con los dirigentes de las estructuras sindicales más representativas e interlocutores que tenían profesiones como académicos, médicos, economistas, militares, etcétera. Las mujeres hablan de temas sobre belleza, violencia de género, emocionales o relacionados con reality shows.

La importancia de los análisis de género reside en que muestran si en los debates televisivos sobre estos temas realmente profundizan en las causas y los consideran un problema de una sociedad androcéntrica y patriarcal, o lo consideran como problemas aislados, de "algunas mujeres", sin educación y con pocos recursos económicos, o con algún problema social. Por ello, es muy importante subrayar la importancia de formar también a los profesionales de la comunicación y sobre todo que a la hora de escribir las noticias tengan en cuenta las peculiaridades y el enfoque de igualdad. Esta es una de las formas de contribuir para que los contenidos sean emitidos con los mismos valores morales y de igualdad, bien sean hechas por hombres o por mujeres. De la misma forma presionar a las entidades reguladoras o educacionales para su responsabilidad social y democrática.

\section{Bibliografía}

Alexanian, A. (2009). Género y medios de comunicación. Indera.

Recuperado el 6 de junio de 2015 de: http://www.gutierrez-rubi.es/wpcontent/uploads/2009/06/femdissabte_amanda-alexanian_version-final.pdf

Leal, S.M.C.; Lopes, M.J.M.; Gaspar, M.F.M. (2011). Social representations of violence against women in the nursing perspective. Interface - Comunic., Saude, Educ. Recuperado el 3 de mayo de 2015 de: http://www.scielo.br/pdf/icse/v15n37/aop0911.pdf

Lopes, F.A (2007). SIC e TVI longe das recomendações da ERC. Comunicação apresentada no $5^{\circ}$ SOPCOM, 7 de Setembro, Universidade do Minho. Recuperado el 4 de abril de 2015 de: http://repositoriun.sdun.uninho.pt/bitstream/1822/8732/3/Lopes_2007_SIC\%2c \%20TVI\%20e\%20ERC.pdf

Lopes, F.B (2007). Homens públicos, mulheres privadas - a presença da mulher na informação televisiva. Universidade do Minho. 
Recuperado el 4 de abril de 2015 de: http://repositoriun.sdun.uninho.pt/bitstream/1822/8614/3/Lopes_2007 hpublicos mprivadas.pdf

Lopes, F. (2011). Quando o lugar da redação condiciona a composição do plateau informativo: análise do noticiário À Noite, as Notícias (RTPN). ${ }^{2}$

Mattelart, M. (1981). La mujer y las industrias culturales. Uned. Recuperado el 1 de junio de 2015 de: http://unesdoc.unesco.org/images/0004/000484/048493SB.pdf

Ríos, M. J.; Martínez, J. (1997). La mujer en los medios. Comunicar. Recuperado el 6 de junio de 2015 de: http://www.redalyc.org/articulo.oa?id=15800914

Rovetto, F. (2010) Apuntes sobre la representación de las mujeres en la prensa de la actualidad. Androcentrismo y medios de comunicación. Recuperado el 6 de junio de 2015 de:file:///C:/Users/jonri/Downloads/DialnetAndrocentrismoYMediosDeComunicacion-3384508.pdf

Santibáñez Velilla, J., Renés Arellano, P., \& Ramírez García, A. (2012). Ciudadanía y competencia audiovisual en La Rioja: Panorama actual en la tercera edad. Revista ICONO14 Revista Científica De Comunicación Y Tecnologías Emergentes, 10(3), 159-175. Recuperado el 6 de junio de 2015 de: https://doi.org/10.7195/ri14.v10i3.195

Fueyo Gutiérrez, A., Navarro Martínez, E. (2011) A formación en xornalismo especializado en educación dende a perspectiva de xénero: apuntes para unha proposta metodolóxica. En Luís Álvarez Pousa y Belén Puñal Rama (coords.) (2011) Rompendo moldes. Áreas de especialización e Xénero no Xornalismo. Santiago de Compostela, Editorial Atlántica.

Abril, G. (1997). Teoría General de la Información. Madrid: Cátedra.

\footnotetext{
${ }^{2}$ Texto inédito, cortesía de la autora.
} 